South African Journal of Animal Science 2020,50 (No. 4)

\title{
Effects of heat stress on the hepatic transcriptome of yellow-feathered chickens
}

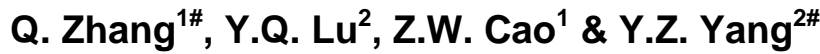 \\ ${ }^{1}$ College of Coastal Agricultural Sciences, Guangdong Ocean University, Zhanjiang 524088, China \\ ${ }^{2}$ Beijing General Station of Animal Husbandry, Beijing 100101, China
}

(Submitted 9 June 2020; Accepted 21 August 2020; Published 2 October 2020)

Copyright resides with the authors in terms of the Creative Commons Attribution 4.0 South African Licence.
See: http://creativecommons.org/licences/by/4.0/za
$\begin{array}{r}\text { Condition of use: The user may copy, distribute, transmit and adapt work, but must recognise the authors and the South African Journal } \\ \text { of Animal Science. }\end{array}$

\begin{abstract}
Heat stress is one of the main environmental factors that hamper the efficiency of poultry production. Heat stress is known to be less harmful to yellow-feathered chickens (YFC) than to commercial broilers, especially in its effect on the relative weight of organs. The transcriptome was used to examine the gene expression profile of the livers of YFC that were exposed to heat stress. Mean liver weight (HW) and the hepatic weight index (HWI) of birds in the heat stress group did not differ significantly from those of the control group. A total of 596 genes were differentially expressed in the liver in response to heat stress. The enrichment results of differentially expressed genes (DEG) showed that many of these genes were related to the Fanconi anaemia pathway and that the cell cycle pathway was modulated. Thus, it can be concluded that these genes might be involved in improving the stability of the YFC liver genome and controlling the physiological response to heat stress.
\end{abstract}

Keywords: , heat stress, liver, transcriptome, yellow-feathered chickens

"Corresponding authors: yyz84929056@126.com and zhang_quan@cau.edu.cn

\section{Introduction}

Yellow-feathered chickens are less affected by heat stress than commercial broilers, especially for its effect on weight gain (Azad et al., 2010; Zhang et al., 2019). Transcriptome studies are an effective method of analysing tissue gene expression and can be used to study the effect of heat stress on poultry. At a phenotypic level, the decreased growth performance that is observed in poultry exposed to heat stress affects the relative weights of various tissues (Quinteirofilho et al., 2010; Zhang et al., 2017; Zhang et al., 2019). This might be interpreted to indicate that heat stress can suppress tissue cell proliferation at various rates depending on the organ.

Liver tissue has been shown to be more susceptible to heat stress than that of other organs (Lin et al., 2006). Differences in gene expression related to the cell cycle in liver of white Leghorn chickens indicated their down-regulation under heat stress (Sun et al., 2015). Coble et al. (2014) examined the liver transcriptome of broilers that had been exposed to heat stress and found that 40 differentially expressed genes (DEG) were involved in cell signalling and the development and function of the endocrine system. A parallel study by the same group analysed the transcriptome of YFC liver tissue exposed to acute heat stress, and found 834 DEG, almost half of which were involved in lipid and energy metabolism (Zhang et al., 2020). In YFC that were exposed to chronic heat stress, an RNA-seq analysis of heart tissue revealed 37 DEG that were involved in oxidative phosphorylation and cardiac muscle contraction pathways (Zhang et al., 2019). However, to the authors' knowledge, a transcriptomic study has not been undertaken on livers of YFC exposed to chronic heat stress. Therefore, the goal of this study was to compare the transcriptomes of YFC subjected to heat stress $\left(38 \pm 1{ }^{\circ} \mathrm{C}\right.$ for eight hours/day over seven days) with the transcriptome of similar birds in a non-stressful environment.

\section{Materials and Methods}

Twelve 17-day-old male YFC were selected, divided into two equal groups (control and heat stress), and placed in two environmentally controlled rooms for a five-day acclimatization period. The period of heat stress consisted of seven days. It started after the acclimatization, when the YFC were 22 days old and ended when they were 28 days old. During acclimatization and the experimental period, the YFC were 
provided with ad libitum access to food and water. The heat stress group was exposed to the temperature of $38 \pm 1^{\circ} \mathrm{C}$ for 8 hours each day $(9 \mathrm{~h} 00-17 \mathrm{~h} 00)$ and was kept at $25 \pm 1^{\circ} \mathrm{C}$ for the rest of the time. The control group was kept at $25 \pm 1^{\circ} \mathrm{C}, 24$ hours a day. Bodyweight (BW) and cloacal temperature (CT) were measured according to (Zhang et al., 2020; Zhang et al., 2019). All 28-day-old YFC from the treatment and control groups were euthanized at the end of the final day of the heat stress treatment, and their livers were removed. Their hepatic weight (HW) was determined, and the hepatic weight index (HWI) was calculated $(\mathrm{HWI}=\mathrm{HW} / \mathrm{BW} \times 100 \%)$. Twelve liver tissue samples (six control and six heat stress group) were collected and stored at $-80^{\circ} \mathrm{C}$ for further study. All YFC were cared for and treated in accordance with the Guangdong Ocean University Animal Care and Use Committee guidelines (permit number SYXK 2014-0053).

The total RNA of each liver sample was extracted using TRIzol reagent (Invitrogen) in accordance with the manufacturer's instructions. The RNA-seq libraries of each sample were prepared with the RNA Library Prep Kit for Illumina, according to the manufacturer's recommendations. Illumina HiSeq 4000 platform was used to sequence the 12 individual liver RNA libraries. The software HISAT2 (v2.0.5) was used to map the sequences to the Gallus gallus genome assembly (Kim et al., 2015), and gene expression levels were quantified as fragments per kilobase million (Trapnell et al., 2010). The DEG analysis was conducted using DESeq (1.16.1) (Anders \& Huber, 2010) $(P<0.05)$ (false discovery rate $(F D R)<0.01)$. The functional groups of DEG were determined using DAVID 6.8. All RNA-seq raw data have been submitted to the sequence read archive (SRA) under SRA number PRJNA627128.

The 16 DEG were determined with qRT-PCR, and the $2^{-\triangle \Delta C T}$ method (Livak \& Schmittgen, 2001) was used to analyse the gene expression levels. The primer pairs are shown in Table 1. The values of BW, HW, HWI, CT and qRT-PCR were analysed with one-way analysis of variance (ANOVA) with SPSS software (v19.0).

Table 1 Forward and reverse primers used for QPCR validation of RNA-seq

\begin{tabular}{lllc}
\hline Gene name & Forward primer & Reverse primer & Product length \\
\hline FANCA1.64 & TGCGATCGTGTTCCTTCAGA & TACCAACAGCATCGAGGACC & $131 \mathrm{bp}$ \\
FANCG1.66 & TCAAGGCATGGAGAACACCT & GCAAAGGGTAGTGGAGAGGT & $146 \mathrm{bp}$ \\
FANCI0.94 & TCCTGCCTCCACTGAAACTT & TACCAGGCTAGACAGTGCTG & $112 \mathrm{bp}$ \\
PMS2 & CTCTCAGTTCGTTGTGTGCA & TGCTCACAGTTGTTCCTTGC & $147 \mathrm{bp}$ \\
APITD1 & AGACCTCGAGATGTTTGCCA & GCAAGCTCGTCACTCTTCTG & $123 \mathrm{bp}$ \\
BRCA1 & ACAACAGGGTCAAAGGGTCT & TAACCCAGTACTGCTTGCCA & $128 \mathrm{bp}$ \\
BUB1 & GGAGCAGAAGTGGTCCAGA & TTCATCCTGCTGCTTTGCTC & $123 \mathrm{bp}$ \\
E2F1 & AGCCACTCAGTACCTATGCC & TCCTTCTCCAACCAAGCTGT & $122 \mathrm{bp}$ \\
MAD2L1 & TTCTGCCCAGGATGTGAACA & AAATCGTCCTTGCCATGCTC & $141 \mathrm{bp}$ \\
WEE1 & GAGTGTGACAAGAACGCCAG & CAGTTTCCAGGAGAGGCAGA & $130 \mathrm{bp}$ \\
CDC20 & AGAGCTGAAGGACCTACTGC & CACCGACGTCCTGGATATGA & $115 \mathrm{bp}$ \\
CCNA2 & TGCACCAGAGATTCGCAATG & GCAGCTGAATGATTTCCCCA & $128 \mathrm{bp}$ \\
CDK1 & TGTCAGCGATATCCACACGT & CCAGCCAGTCCACCAGAATA & $122 \mathrm{bp}$ \\
MCM6 & AGGGGTGATAAACTGGCAGA & CCTCTGGAGACCTGTACCAC & $104 \mathrm{bp}$ \\
PLK1 & ACACAGCCAAACATCTGCAG & GCCTGAGTCTCTTGAATGCG & $116 \mathrm{bp}$ \\
GAPDH & TGTCCCTCTGCCTTGAACAA & CACGTGCAGAGGTAGGGTAA & $140 \mathrm{bp}$ \\
& TAGTGAAGGCTGCTGCTGAT & AAGGTGGAGGAATGGCTGTC & $103 \mathrm{bp}$ \\
\hline
\end{tabular}

\section{Results and Discussion}

The mean BW at the age of 28 days (BW28) of the heat stress group was lower $(P=0.047)$ than that of the control (Figure 1A). The HW and HWI of the heat stress group did not differ from those of the control $(P=0.100$ and $P=0.911)$, indicating normal physiological development of the liver (Figure 1B, 1D). The current measurements of the CT showed that the heat stress treatment $\left(38 \pm 1^{\circ} \mathrm{C}\right)$ caused a significantly elevated CT in YFC (Figure 1C). 

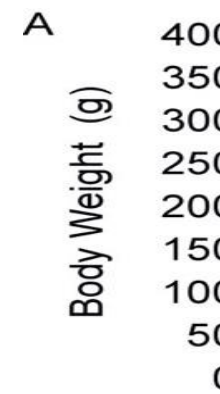

400
350
300
250
200
150
100
50
0

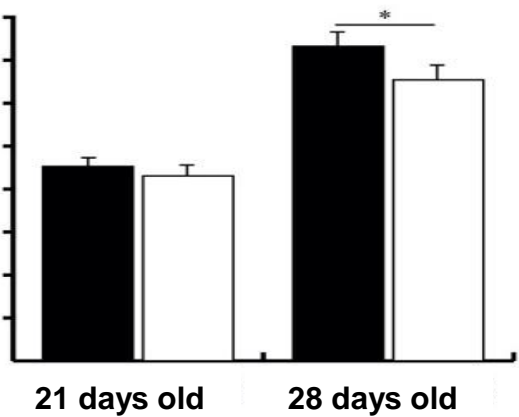

C

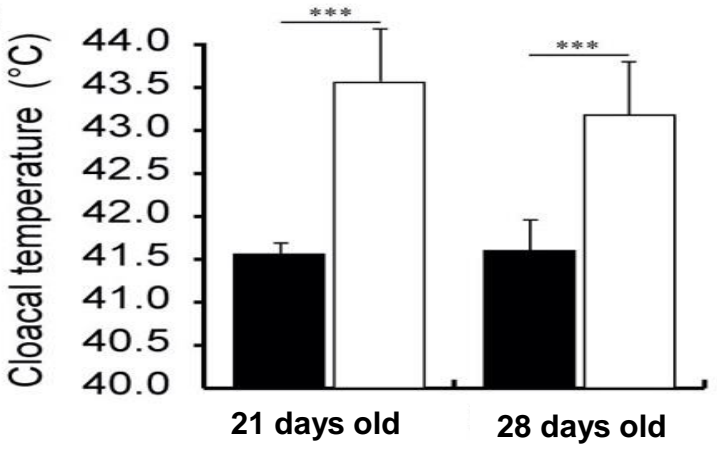

B

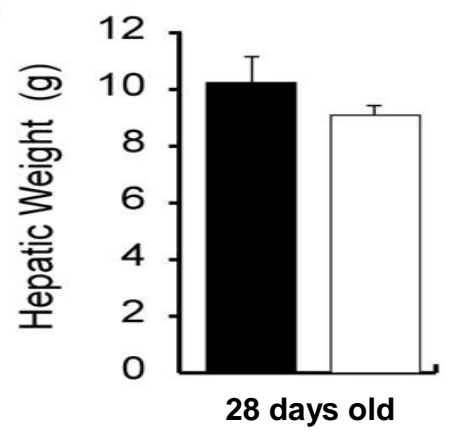

$\mathrm{D}$

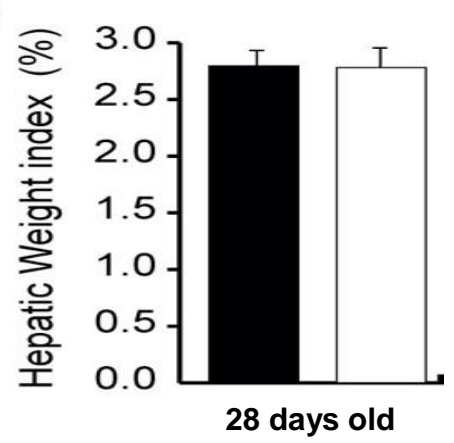

Figure 1 Mean ( \pm SE) bodyweight $(A)$, hepatic weight $(B)$, cloacal temperature $(C)$ and hepatic weight index (D) of yellow-feathered chickens subjected to heat stress (open bars) and contemporary control birds (solid bars $){ }^{*}(P<0.05)$ and ${ }^{* * *}(P<0.001)$

The total clean reads of these DEG ranged from 43 to 52 million, and approximately $93 \%$ of the clean reads were mapped to the reference genome of the chicken, of which $78 \%$ were mapped to exons (Table 2). A total of $596 \mathrm{DEG}(P<0.05$, FDR $<0.01)$ were found in response to heat stress in their livers (Figure 2). The 368 and 228 were up-regulated and down-regulated expressions. The log2 (fold change) induced by heat stress ranged from -6.33 to 8.54 .

Table 2 Number of raw, clean, mapped and uniquely reads for hepatic transcriptome of yellow-feathered chickens subjected to heat stress and contemporary control birds

\begin{tabular}{lllccc}
\hline cDNA library & Raw reads & Clean reads & Mapped reads & Uniquely mapped & Exon mapped (\%) \\
\hline Control 1 & $46,408,340$ & $44,705,112$ & $42,214,283$ & $41,202,210$ & 83.34 \\
Control 2 & $51,286,396$ & $49,489,496$ & $46,795,734$ & $45,676,045$ & 82.77 \\
Control 3 & $46,890,308$ & $45,026,922$ & $42,655,688$ & $41,640,537$ & 83.66 \\
Control 4 & $46,837,116$ & $44,498,392$ & $40,560,906$ & $39,809,319$ & 73.05 \\
Control 5 & $45,924,804$ & $43,796,568$ & $40,135,752$ & $39,426,354$ & 71.36 \\
Control 6 & $45,741,030$ & $43,586,872$ & $39,330,746$ & $38,572,107$ & 74.10 \\
HS group 1 & $47,229,822$ & $45,163,122$ & $42,687,367$ & $41,657,734$ & 82.57 \\
HS group 2 & $47,381,304$ & $45,276,764$ & $42,951,268$ & $41,773,468$ & 83.71 \\
HS group 3 & $45,788,802$ & $43,814,718$ & $41,424,514$ & $40,302,827$ & 83.65 \\
HS group 4 & $47,321,782$ & $45,177,940$ & $41,519,533$ & $40,800,706$ & 73.30 \\
HS group 5 & $53,435,846$ & $51,197,804$ & $47,057,005$ & $46,270,076$ & 71.42 \\
HS group 6 & $46,292,372$ & $44,238,778$ & $40,599,199$ & $39,911,081$ & 72.44 \\
Average & $47,544,826$ & $45,497,707$ & $42,327,666$ & $41,420,205$ & 77.95 \\
\hline
\end{tabular}




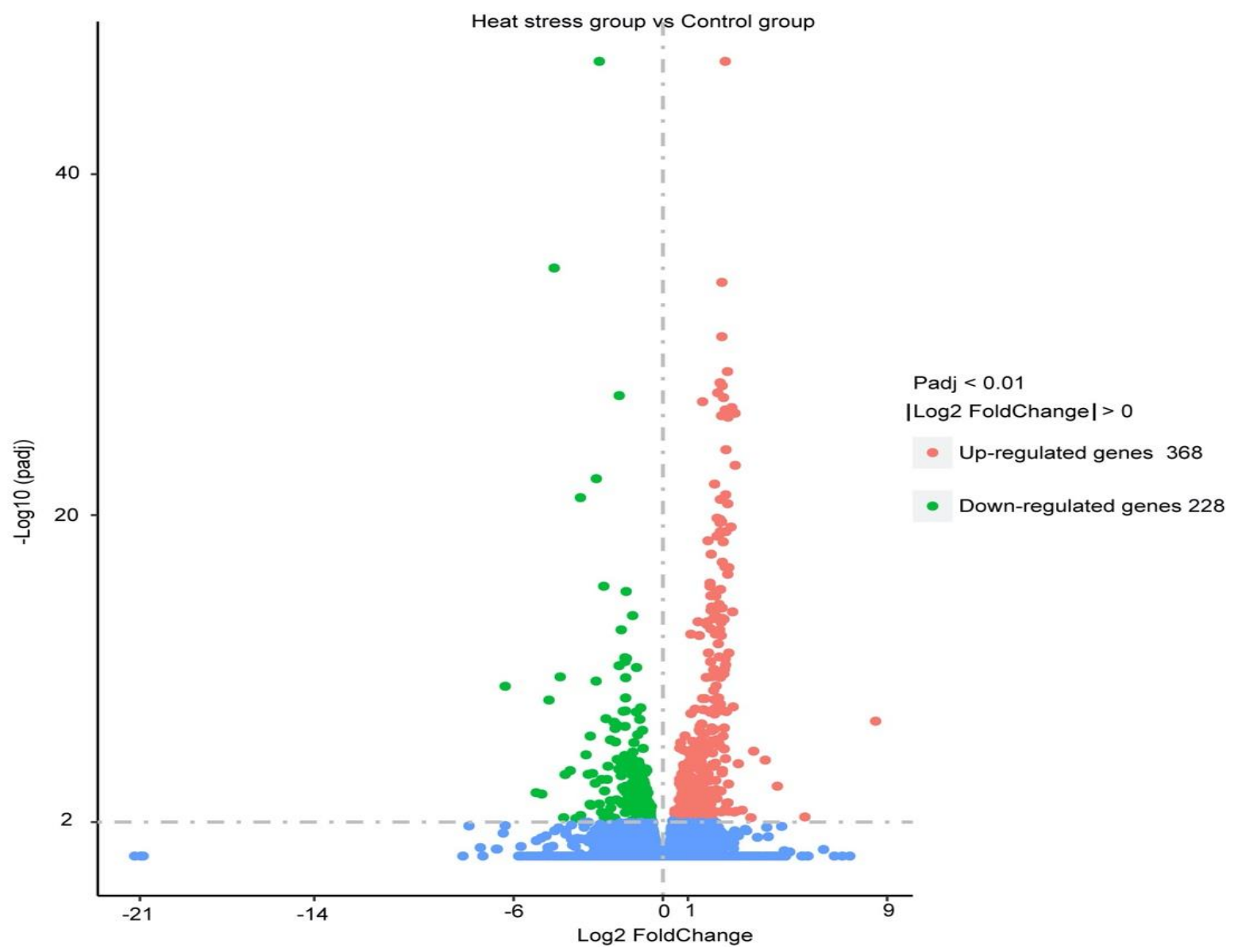

Figure 2 Volcano plot of differentially expressed genes in heat stress yellow-feathered chickens compared with the control birds

DAVID (Huang et al., 2009) was used to analyse the gene ontology terms for DEG to investigate the biological processes related to heat stress. The enriched biological process terms (FDR $<0.05)$ of the DEG expressed in the liver were related to chromosome segregation and cell division (Figure 3). The Kyoto encyclopaedia of genes and genomes (KEGG) (Kanehisa \& Goto, 1999) pathway analysis of these DEG revealed the enrichment of two pathways $(P<0.05$, FDR $<0.01)$, namely the Fanconi anaemia pathway and the cell cycle pathway (Table 3). Ten DEG (FANCA, FANCG, FANCI, PMS2, APITD1, BRCA1, BRCA2, $E M E 1, P O L N$, and $U B E 2 T)$ were associated with the Fanconi anaemia pathway, whereas fourteen (BUB1, E2F1, MAD2L1, TTK, WEE1, CDC20, CDC45, CCNA2, CCNB2, CDK1, CDKN2C, MCM6, PTTG1, and $P L K 1)$ were associated with the cell cycle pathway. Interestingly, these DEG were up-regulated in the current experiment and verified by qRT-PCR (Figure 4). The current results suggest that the liver of YFC might provide a molecular mechanism defending against heat stress. 
Table 3 KEGG pathway enriched analysis for differentially expressed genes

\begin{tabular}{|c|c|c|c|c|}
\hline KEGG pathway & $P$-value & FDR & Gene names & Gene description \\
\hline $\begin{array}{l}\text { Fanconi anaemia } \\
\text { pathway }\end{array}$ & $1.54 \mathrm{E}-05$ & 0.017 & $\begin{array}{l}\text { FANCA } \\
\text { FANCG } \\
\text { FANCI } \\
\text { PMS2 } \\
\text { APITD1 } \\
\text { BRCA1 } \\
\text { BRCA2 } \\
\text { EME1 } \\
\text { POLN } \\
\text { UBE2T }\end{array}$ & $\begin{array}{l}\text { Fanconi anaemia complementation group A } \\
\text { Fanconi anaemia complementation group G } \\
\text { Fanconi anaemia complementation group I } \\
\text { PMS1 homolog } 2 \\
\text { Centromere protein S } \\
\text { Breast cancer } 1 \\
\text { Breast cancer } 2 \\
\text { Essential meiotic structure-specific endonuclease } 1 \\
\text { Polymerase (DNA) Nu } \\
\text { Ubiquitin conjugating enzyme E2 T }\end{array}$ \\
\hline Cell cycle & $3.78 \mathrm{E}-05$ & 0.042 & $\begin{array}{l}\text { BUB1 } \\
\text { E2F1 } \\
\text { MAD2L1 } \\
\text { TTK } \\
\text { WEE1 } \\
\text { CDC20 } \\
\text { CDC45 } \\
\text { CCNA2 } \\
\text { CCNB1 } \\
\text { CDK1 } \\
\text { CDKN2C } \\
\text { MCM6 } \\
\text { PTTG2 } \\
\text { PLK1 }\end{array}$ & $\begin{array}{l}\text { BUB1 mitotic checkpoint serine/threonine kinase } \\
\text { E2F transcription factor } 1 \\
\text { MAD2 mitotic arrest deficient-like } 1 \\
\text { TTK protein kinase } \\
\text { WEE1 G2 checkpoint kinase } \\
\text { Cell division cycle } 20 \\
\text { Cell division cycle } 45 \\
\text { Cyclin A2 } \\
\text { Cyclin B1 } \\
\text { Cyclin-dependent kinase } 1 \\
\text { Cyclin-dependent kinase inhibitor } 2 \mathrm{C} \\
\text { Minichromosome maintenance complex component } 6 \\
\text { Pituitary tumour-transforming } 2 \\
\text { Polo like kinase } 1\end{array}$ \\
\hline
\end{tabular}

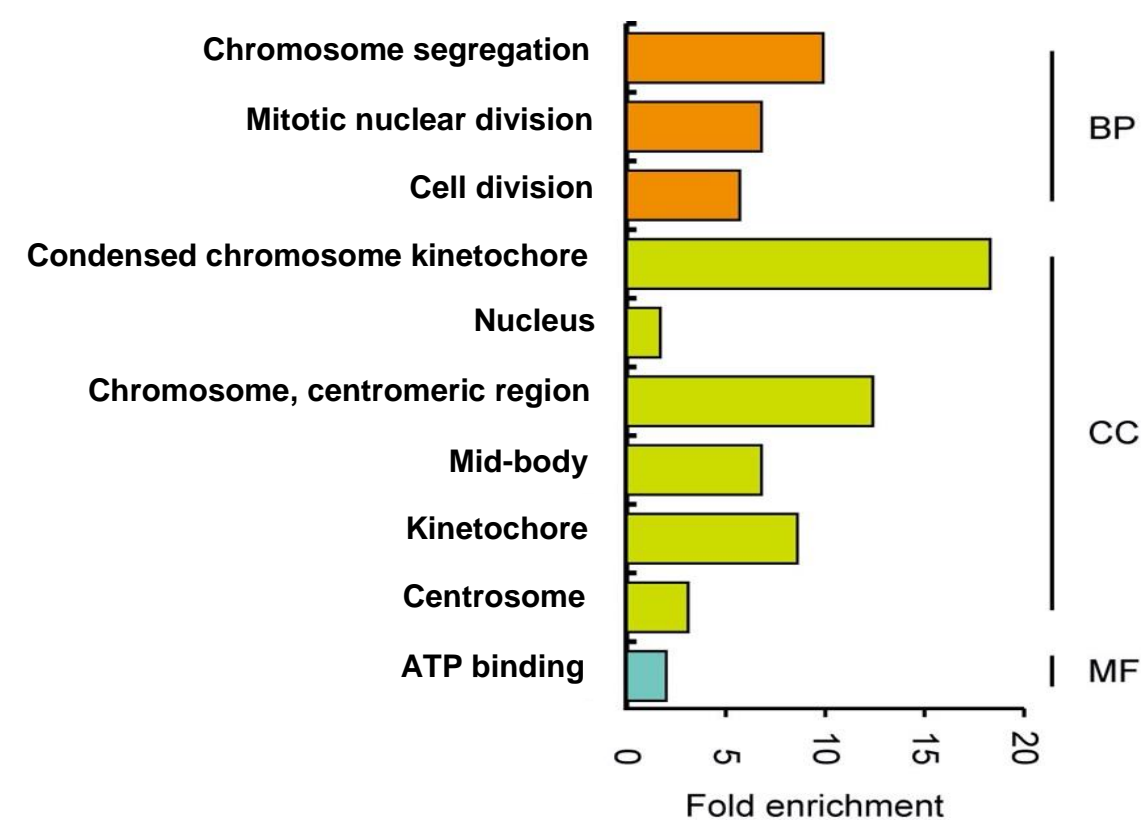

Figure 3 Histogram displaying gene ontology terms of differentially expressed genes enrichment in group subjected to heat stress

BP: biological processes, CC: cellular components, MF: molecular functions 


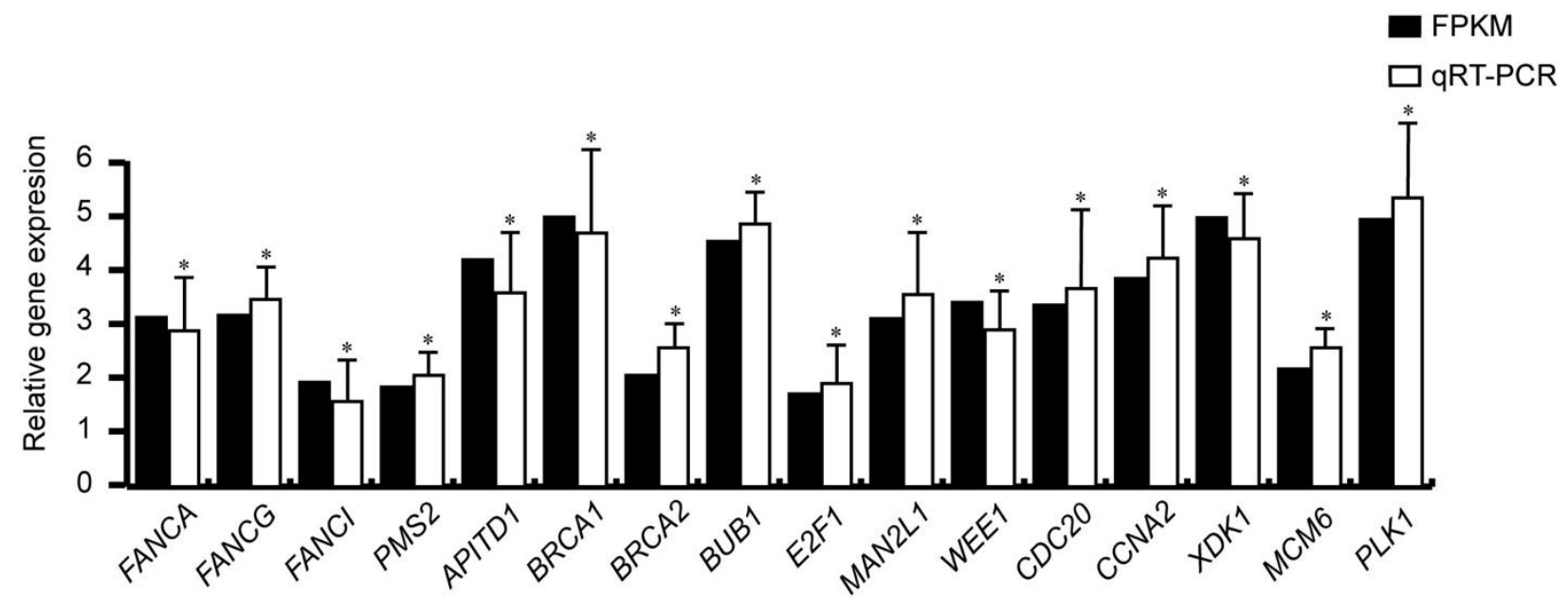

Figure 4 Validation of gene expression of differentially expressed genes in KEGG enrichment pathway ${ }^{*}$ Represents genes with significant differential expression $(P<0.05)$

After exposure to heat stress, the BW gain in YFC decreased by $9.9 \%$ and the BW gain ratio was $55.7 \%$. In a study of chickens under heat stress conditions, the BW gain between 21 and 28 days of age in broilers decreased by 18\% (Azad et al., 2010). In Advanced Intercross Line chickens bred for thermotolerance (Deeb \& Lamont, 2002), exposure to heat stress resulted in a reduction of BW gain by $58.9 \%$ (Angelica et al., 2015). The similarity of these rates suggests that YFC can adapt to high ambient temperatures (Deeb \& Lamont, 2002; Van Goor et al., 2015). In poultry, relative weights of tissue are usually assessed as indicators of physiological development (Van et al., 2013). Previous studies have shown that the heat stress-driven decline in the growth performance of fast-growing broilers has varying effects on organs, including the relative weight reduction of the spleen, thymus, bursa, and heart (Quinteirofilho et al., 2010; Zhang et al., 2017), but no significant difference in relative heart weight was found in slow-growing chickens and YFC under chronic heat stress (Zhang et al., 2017; Zhang et al., 2019). In the present study, the authors found that HWI was not affected significantly by chronic heat stress, and they observed normal physiological development of the liver in the treatment group YFC (Van et al., 2013). In birds, body temperature is commonly recorded in the rectum (Poole \& Stephenson, 1977) and the current result is in line with previous studies, which showed that chicken body temperature increased significantly under heat stress (Cooper \& Washburn, 1998; Feng, 2010; Zhang et al., 2020).

In contrast, only $37 \mathrm{DEG}$ (FDR $<0.1$ ) were identified in the heart transcriptome of YFC subjected to heat stress in a previous study (Zhang et al., 2019). The current findings (596 DEG) suggest that the liver of YFC is more susceptible to heat stress than the heart. In terms of gene ontology, the biological processes affected by the DEG in the liver were related to chromosome segregation and cell division. A study on a hepatocellular cell line of male white Leghorns found that heat stress affected the expression of genes related to DNA replication, DNA repair, and chromosome segregation (Sun et al., 2015). The KEGG pathway analysis of these DEG revealed the enrichment of the Fanconi anaemia pathway and the cell cycle pathway. Interestingly, while these DEG were up-regulated in the current experiment, the expression of DEG related to the cell cycle had previously been down-regulated in liver cell line of white Leghorn chickens under heat stress (Sun et al., 2015). These results suggest that the response of tissues to heat stress is different from that of cell lines. This might be related to the genetic composition of the species, genomic variations, and the nature of heat stress (Sonna et al., 2002).

The role of the Fanconi anaemia pathway and its proteins is to maintain genomic stability through responses to replication, and oxidative and mitotic stress (Palovcak et al., 2017). For instance, PMS2 is a mismatch repair gene, coding for a mismatch repair endonuclease, which maintains the stability of the genome by correcting the base mismatches and insertion-deletion mismatches during DNA replication and recombination (Sameer et al., 2014). Replication stress occurs when the DNA secondary structure, DNA damage, or another factor, blocks the DNA replication mechanism and leads to stagnation (Cortez \& David, 2015). Inter-strand crosslinks (ILCs) are one of the factors which can cause replication stress by completely blocking the progress of the replication fork and inhibiting DNA replication and RNA transcription (Clauson et al., 2013). Fanconi anaemia proteins assist in the recovery of replication forks that were stalled because of ICLs. The product of the FANCA gene, which was up-regulated in the current study, has DNA-binding activity and regulates the activity of the crossover junction endonuclease EME1 (encoded by the EME1 
gene, which was also up-regulated in the current results) in an ICL damage-dependent manner (Benitez et al., 2013), which could help to verify ICL damage. The function of the EME1 product is in DNA repair and maintaining genome integrity. An EME1 deficiency has been shown to cause spontaneous genomic instability (Abraham, 2003). Furthermore, the POLN gene codes for a DNA polymerase (Marini et al., 2003), which participates in ICL repair (Bernard et al., 2017; Zietlow et al., 2009).

Fanconi anaemia pathway proteins can also maintain genome stability by preventing oxidative damage. Reactive oxygen species (ROS) are a known source of DNA damage that can drive genomic instability. Exogenous ROS can arise from heat stress. Under the conditions of oxidation, the proteins coded for by FANCA and FANCG were induced to be monoubiquitinated (Park et al., 2004). Fanconi anaemia proteins and UBE2T monoubiquitination have been shown to be necessary to limit DNA damage (Alpi et al., 2007). The FANCG protein interacts with cytochrome P4502E1 to support the roles of Fanconi anaemia proteins in redox metabolism (Makoto et al., 2002). Fanconi anaemia proteins, specifically FANCA, could protect the promoters of antioxidant genes from oxidative stress (Wei et al., 2012).

The Fanconi anaemia pathway is also involved in the regulation of chromosomal abnormalities in mitosis to maintain chromosomal stability (Naim \& Rosselli, 2009). The current results indicate that one function of the Fanconi anaemia pathway may be to respond to a harmful cellular environment that is caused by oxidative damage. $\mathrm{FANCI}$ has been shown to be involved in maintaining chromosome stability (Dorsman et al., 2014). The FANCA gene was demonstrated to be related to genome stability in the G2/S phase of mitosis, and DNA replication in the S phase (Howlett et al., 2005). The product of BRCA1 is involved in the G2/M checkpoint activation and repair of DNA damage (Zhu \& Dutta, 2006). The gene APITD1 promotes the Fanconi anaemia proteins to chromatin. In the light of this research, the current results indicate that the upregulation of the genes related to the Fanconi anaemia pathway in the liver of YFC may be responsible for regulating gene stability in response to heat stress.

The current analysis of the up-regulated DEG related to the cell cycle pathway indicated that they may also be involved in regulating DNA replication, repair, and mitosis in response to heat stress. The process of eukaryotic cell proliferation includes G1, S, G2, and M phases (Bell \& Dutta, 2002). CDC45 codes for a DNA replication factor that participates in the activity of DNA helicase in MCM6 ensures the correct loading of DNA polymerase, and is involved in the unwinding of DNA for initial DNA replication (Depamphilis et al., 2006; Jeannine et al., 2015). CCNA2 is a highly conserved family of cyclins (Ko et al., 2013), which regulate the initiation and progress of the $S$ phase (Yam et al., 2002) and interact with CDK1 to regulate the cell cycle control of the G2/M transition (Arsic et al., 2012; Pagano et al., 1992). The product of the PTTG1 gene is involved in the repair of DNA damage, and is up-regulated during cell replication (Vlotides et al., 2007), and overexpression of the PTTG1 protein was shown to promote cell-cycle progression and cell proliferation (Zhang et al., 1999) and it is considered a cell cycle regulator in the G1/S and G2/M transitions (Vlotides et al., 2007). WEE1 has been shown to be a kinase involved in the cell cycle, regulating the G2 checkpoint block caused by DNA damage (Wang et al., 2004) for pre-mitotic DNA repair (Raleigh \& O'Connell, 2000). The MAD2L1 (Zhang \& Lees, 2001), CDC20 (Shi et al., 2017), BUB1 (Kim et al., 2015), and TTK (Yu et al., 2015) code for the components of the spindle physical examination protein. These genes regulate the transition from the metaphase to the anaphase of the $M$ phase by monitoring the attachment of sister chromatids to the spindle to ensure the fidelity of chromosome separation and genome stability (May \& Hardwick, 2006). The function of the product of PLK1 is mainly to regulate the M phase (Takaki et al., 2008). Depletion of PLK1 has been shown to cause mitotic arrest (Lei \& Erikson, 2008), while the knockout of PLK1 caused embryo death in mice (Lu et al., 2008). In light of previous studies, the authors concluded that the up-regulation of the cell cycle genes observed in the liver of YFC is probably adaptive, and is responsible for the maintenance of normal DNA replication, repair and mitosis in liver under heat stress conditions.

\section{Conclusion}

The current findings provide evidence for the transcriptomic regulation of heat stress responses in the liver of YFC. A total of 596 DEG were detected to be involved in the heat stress response of the YFC liver. The DEG associated with the Fanconi anaemia pathway may be involved in heat stress-related genome stability. Meanwhile, the DEG associated with the cell cycle pathway may be involved in DNA replication, repair, and mitosis during cell proliferation. In the present study, these DEG were up-regulated in the heat stress group. The authors concluded that these genes may be involved in improving the stability of the YFC liver genome and may control the physiological response to heat stress. The current results provide insight into the potential mechanisms of YFC to protect against this important environmental stressor. In addition, this study should provide important insight into future efforts to improve the ability of species to withstand heat stress through genome-wide association studies and breeding.

\section{Acknowledgments}


Work was financed by Guangdong Ocean University Research System, project no. 101402/R17030, $100102 / 524000087290,101401 / 570119049$ and Animal Genetics Resources Protection and Utilization Project in 2019 of Beijing (20190306111108).

\section{Authors' Contributions}

YZY and QZ designed the study, QZ, YQL and ZWC performed the experiment. QZ and YQL analysed the data. QZ contributed to the writing of the manuscript. All the authors agreed with the final version to be submitted.

\section{Conflict of Interest Declaration}

The authors certify they have no conflicting interests regarding the material discussed in the manuscript.

\section{References}

Abraham, J., 2003. EME1 is involved in DNA damage processing and maintenance of genomic stability in mammalian cells. Embo. J. 22, 6137-6147.

Alpi, A.F., Langevin, F., Mosedale, G., Machida, Y.J., Dutta, A. \& Patel, K.J., 2007. UBE2T, the Fanconi anemia core complex, and FANCD2 are recruited independently to chromatin: A basis for the regulation of FANCD2 monoubiquitination. Mol. Cell. Biol. 27, 8421-8430.

Anders, S. \& Huber, W., 2010. Differential expression analysis for sequence count data. Genome Biol. 11, 1-12.

Arsic, N., Bendris, N., Peter, M., Begon-Pescia, C., Rebouissou, C., Gadéa, G., Bouquier, N., Bibeau, F., Lemmers, B. \& Blanchard, J.M., 2012. A novel function for cyclin A2: Control of cell invasion via RhoA signaling. J. Cell Biol. 196, 147-162.

Azad, K.M.A., Kikusato, M., Hoque, A.M, \& Toyomizu, M., 2010. Effect of chronic heat stress on performance and oxidative damage in different strains of chickens. J. Poult. Sci. 47, 333-337.

Bell, S.P. \& Dutta, A., 2002. DNA replication in eukaryotic cells. Annu. Rev. Biochem. 71, 333.

Benitez, A., Yuan, F., Nakajima, S., Wei, L., Qian, L., Myers, R., Hu, J.J., Lan, L. \& Zhang, Y., 2013. Damage-dependent regulation of MUS81-EME1 by fanconi anemia complementation group A protein. Nucleic Acids Res. 42, 1671 1683.

Bernard, F., Althaus, I., Fisher, A., Jasty, V. \& Canman, C., 2017. The role of DNA polymerase Nu and Zeta in the repair of DNA interstrand crosslinks. The FASEB J. 31, 994-996.

Clauson, C., Scharer, O.D. \& Niedernhofer, L., 2013. Advances in understanding the complex mechanisms of DNA interstrand cross-link repair. Cold Spring Harbor Perspect. Biol. 5, a012732.

Coble, D.J., Fleming, D., Persia, M.E., Ashwell, C.M., Rothschild, M.F., Schmidt, C.J. \& Lamont, S.J., 2014. RNA-seq analysis of broiler liver transcriptome reveals novel responses to high ambient temperature. BMC Genomics, 15 , $1-12$.

Cooper, M.A. \& Washburn, K.W., 1998. The relationships of body temperature to weight gain, feed consumption, and feed utilization in broilers under heat stress. Poult. Sci. 77, 237-242.

Cortez, D., 2015. Preventing replication fork collapse to maintain genome integrity. DNA Repair. 32, 149-157.

Deeb, N. \& Lamont, S.J., 2002. Genetic architecture of growth and body composition in unique chicken populations. J. Hered. 93, 107.

Depamphilis, M.L., Blow, J.J., Ghosh., S, Saha, T., Noguchi, K. \& Vassilev, A., 2006. Regulating the licensing of DNA replication origins in metazoa. Curr. Opin. Cell Biol. 18, 231-239.

Dorsman, J.C., Levitus, M., Rockx, D., Rooimans, M.A., Oostra, A.B., Haitjema, A., Bakker, S.T., Steltenpool, J., Schuler, D. \& Mohan, S., 2014. Identification of the Fanconi anemia complementation group I gene, FANCl. Cell. Oncol. 29, 211-218.

Feng, E.J., 2010. Effects of different acute high ambient temperatures on function of hepatic mitochondrial respiration, antioxidative enzymes, and oxidative injury in broiler chickens. Poult. Sci. 89, 115-122.

Gerhardt, J., Guler, G.D. \& Fanning, E., 2015. Human DNA helicase B interacts with the replication initiation protein CDC45 and facilitates CDC45 binding onto chromatin. Exp. Cell Res. 334, 283-293

Howlett, N.G., Toshiyasu, T., Durkin, S.G., D'Andrea, A.D. \& Glover, T.W., 2005. The Fanconi anemia pathway is required for the DNA replication stress response and for the regulation of common fragile site stability. Hum. Mol. Genet. 14, 693-701.

Huang, D.W., Sherman, B.T. \& Lempicki, R.A., 2009. Bioinformatics enrichment tools: paths toward the comprehensive functional analysis of large gene lists. Nucleic Acids Res. 27(1), 1-13.

Kanehisa, M. \& Goto, S., 1999. KEGG: Kyoto Encyclopedia of genes and genomes. Nucleic Acids Res. 28, 27-30.

Kim, D., Langmead, B. \& Salzberg, S.L., 2015. HISAT: A fast spliced aligner with low memory requirements. Nat. Methods, 12, 357-360.

Kim, H.H., Song, H.K., Lee, B.J. \& Park, S.J., 2015. Structural stability of CD1 domain of human mitotic checkpoint serine/threonine-protein kinase, Bub1. J. Kor. Magn. Reson. 19,88-94

Ko, E., Kim, Y., Cho, E.Y., Han, J., Shim, Y.M., Park, J. \& Kim, D.H., 2013. Synergistic effect of BCL-2 and Cyclin A2 on adverse recurrence-free survival in stage I non-small cell lung cancer. Ann. Surg. Oncol. 20, 1005-1012.

Lei, M. \& Erikson, R.L., 2008. PLK1 depletion in nontransformed diploid cells activates the DNA-damage checkpoint. Oncogene. 27, 3935-3943.

Lin, H., Decuypere, E. \& Buyse, J., 2006. Acute heat stress induces oxidative stress in broiler chickens. Comp. Biochem. Physio. A Mol. Integr. Physiol. 144, 11-17.

Livak, K.J. \& Schmittgen, T.D., 2001. Analysis of relative gene expression data using real-time quantitative PCR and the $2\left(^{-\triangle \Delta C T}\right)$ Method. Methods 25, 402-408. 
Lu, L.Y., Wood, J.L., Minter-Dykhouse, K., Ye, L., Saunders, T.L., Yu, X. \& Chen, J., 2008. Polo-like kinase 1 is essential for early embryonic development and tumor suppression. Mol. Cell. Biol. 28, 6870-6876.

Makoto, F., Takehito, I., Shinji, W., Sachiko, K., Atsushi, T., Wang, J. \& Liu, J.M., 2002. The FANCG Fanconi anemia protein interacts with CYP2E1: Possible role in protection against oxidative DNA damage. Carcinogenesis 23, 6772

Marini, F., Kim, N., Schuffert, A. \& Wood, R.D., 2003. POLN, a nuclear polA family DNA polymerase homologous to the DNA cross-link sensitivity protein Mus308. J. Biol. Chem. 278, 32014-32019.

May, K.M. \& Hardwick, K.G., 2006. The spindle checkpoint. J. Cell Sci. 119, 4139-4142.

Naim, V. \& Rosselli, F., 2009. The FANC pathway and BLM collaborate during mitosis to prevent micro-nucleation and chromosome abnormalities. Nat.Cell Biol. 11,761-768.

Pagano, M., Pepperkok, R., Verde, F., Ansorge, W. \& Draetta, G., 1992. Cyclin A is required at two points in the human cell cycle. Embo J. 11, 961-971.

Palovcak, A., Liu, W., Yuan, F. \& Zhang, Y., 2017. Maintenance of genome stability by Fanconi anemia proteins. Cell Biosci. 7, 8.

Park, S.J., Ciccone, S.L.M., Beck, B.D., Hwang, B., Freie, B., Clapp, D.W. \& Lee, S.H., 2004. Oxidative stress/damage induces multimerization and interaction of fanconi anemia proteins. J. Biol. Chem. 279, 30053-30059.

Poole, S. \& Stephenson, J.D., 1977. Core temperature: Some shortcomings of rectal temperature measurements. Physiol. Behav. 18, 203-205.

Quinteirofilho, W.M., Ribeiro, A., Ferrazdepaula, V., Pinheiro, M.L., Sakai, M., Sa, L.R.M., Ferreira, A.J.P. \& Palermoneto, J., 2010. Heat stress impairs performance parameters, induces intestinal injury, and decreases macrophage activity in broiler chickens. Poult. Sci. 89, 1905-1914.

Raleigh, J.M. \& O'Connell, M.J., 2000. The G2 DNA damage checkpoint targets both WEE1 and CDC25. J. Cell Sci. $113,1727-1736$.

Sameer, A.S., Nissar, S. \& Fatima, K., 2014. Mismatch repair pathway: Molecules, functions, and role in colorectal carcinogenesis. Eur. J. Cancer Prev. 23(4), 246-257.

Shi, R., Sun, Q., Sun, J., Wang, X., Xia, W., Dong, G., Wang, A., Jiang, F. \& Xu, L., 2017. Cell division cycle 20 overexpression predicts poor prognosis for patients with lung adenocarcinoma. Tumor Biol. 39, 1010428317692233.

Sonna, L.A., Fujita, J., Gaffin, S.L. \& Lilly, C.M., 2002. Invited review: effects of heat and cold stress on mammalian gene expression. J. Appl. Physiol. 92(4), 1725-1742.

Sun, L., Lamont, S.J., Cooksey, A.M., McCarthy, F., Tudor, C.O., Vijay-Shanker, K., DeRita, R.M., Rothschild, M., Ashwell, C., Persia, M.E. \& Schmidt, C.J., 2015. Transcriptome response to heat stress in a chicken hepatocellular carcinoma cell line. Cell Stress and Chaperones, 20, 939-950.

Takaki, T., Trenz, K., Costanzo, V. \& Petronczki, M., 2008. Polo-like kinase 1 reaches beyond mitosis-cytokinesis, DNA damage response, and development. Curr. Opin. Cell Biol. 20, 650-660.

Trapnell, C., Williams, B.A., Pertea, G., Mortazavi, A., Kwan, G., Baren, M.J.V., Salzberg, S.L., Wold, B.J. \& Pachter, L., 2010. Transcript assembly and quantification by RNA-Seq reveals unannotated transcripts and isoform switching during cell differentiation. Nat. Biotechnol. 28, 511-515.

Van der Ven, L.J.F., Van Wagenberg, A.V., Decuypere, E., Kemp, B. \& Van den Brand, H., 2013. Perinatal broiler physiology between hatching and chick collection in 2 hatching systems. Poult. Sci, 92, 1050-1061.

Van Goor, A., Bolek, K.J., Ashwell, C.M., Persia, M.E., Rothschild, M.F., Schmidt, C.J. \& Lamont, S.J., 2015. Identification of quantitative trait loci for body temperature, body weight, breast yield, and digestibility in an advanced intercross line of chickens under heat stress. Genet. Sel. Evol. 47, 96.

Vlotides, G., Eigler, T. \& Melmed, S., 2007. Pituitary tumor-transforming gene: Physiology and implications for tumorigenesis. Endoc. Rev. 28, 165-186.

Wang, Y., Decker, S.J. \& Sebolt-Leopold, J., 2004. Knockdown of CHK1, WEE1 and MYT1 by RNA interference abrogates G2 checkpoint and induces apoptosis. Cancer Biol. Ther. 3, 305-313.

Wei, D., Rani, R., Sipple, J., Schick, J. \& Pang, Q., 2012. The FA pathway counteracts oxidative stress through selective protection of antioxidant defense gene promoters. Blood 119, 4142-4151.

Yam, C.H., Fung, T.K. \& Poon, R.Y.C., 2002. Cyclin A in cell cycle control and cancer. Cell. Mol. Life Sci. 59, $1317-1326$.

Yu, Z.C., Huang, Y.F. \& Shieh, S.Y., 2015. Requirement for human MPS1/TTK in oxidative DNA damage repair and cell survival through MDM2 phosphorylation. Nucleic Acids Res. 44, 1133-1150.

Zhang, J., Schmidt, C.J. \& Lamont, S.J., 2017. Transcriptome analysis reveals potential mechanisms underlying differential heart development in fast- and slow-growing broilers under heat stress. BMC Genomics. 18, 295.

Zhang, Q., Luo, Y.K., Zhang, B.H., Chan, Y.Z., Huang, L.L., Wang, Y., Liang, J.M. \& Zhang, X.Q., 2020. RNA-Seq study of hepatic response of yellow-feather chickens to acute heat stress. Ann. Anim. Sci. 20, 55-69.

Zhang, Q., Zhang, B.H. \& Luo, Y.K., 2019. Cardiac transcriptome study of the effect of heat stress in yellow-feather broilers. Ital. J. Anim. Sci. 18, 971-975.

Zhang, X., Horwitz, G.A., Prezant, T.R., Valentini, A., Nakashima, M., Bronstein, M.D. \& Melmed, S., 1999. Structure, expression, and function of human pituitary tumor-transforming gene (PTTG). Mol. Endocrinol. 13, 156-166.

Zhang, Y. \& Lees, E., 2001. Identification of an overlapping binding domain on CDC20 for MAD2 and anaphasepromoting complex: Model for spindle checkpoint regulation. Mol. Cell. Biol. 21, 5190-5199.

Zhu, W. \& Dutta, A., 2006. An ATR- and BRCA1-mediated fanconi anemia pathway is required for activating the G2/M checkpoint and DNA damage repair upon rereplication. Mol. Cell. Biol. 26, 4601-4611.

Zietlow, L., Smith, L.A., Bessho, M. \& Bessho, T., 2009. Evidence for the involvement of human DNA polymerase N in the repair of DNA interstrand cross-links. Biochemistry 48, 11817-11824. 